\title{
Partnership with social care professionals as a context for promoting self-determination among people with intellectual disabilities
}

\author{
Annick Cudré-Mauroux*, Geneviève Piérart, Carla Vaucher \\ University of Applied Sciences and Arts Western Switzerland / HES-SO, School of Social Work Fribourg, Route des Arsenaux $16 a$, 1700 Fribourg, \\ Switzerland
}

\section{A R T I C L E I N F O}

Number of completed reviews is 3

Keywords:

Self-determination

Intellectual disabilities

Social care relationship

Professional practices and attitudes

Partnership

\begin{abstract}
A B S T R A C T
Background: People with intellectual disabilities who live in residential facilities may need social support to express self determination. Relationships with social care professionals provide an important context for promoting self-determination. Adopting a socioecological perspective, our study aimed to better understand the nature of these relationships.

Method: Over a period of ten months, we held 13 focus group discussions with a total of 20 participants, including both residents and staff at facilities for people with intellectual disabilities. Using transcripts of these discussions, we analysed expressions of self-determination among people with intellectual disabilities and the responses of social care professionals.

Results: Our results highlight the importance of relational adjustment in fostering self-determination among people with intellectual disabilities and underline the importance of respective roles within relationships between people with intellectual disabilities and social care professionals.

Conclusion: The partnership between people with intellectual disabilities and professionals seems to be the most effective type of relationship in order to support the self-determination of people with intellectual disabilities.

This paper provides a fresh perspective on the role played by people with intellectual disabilities in their relationships with social care professionals. By engaging people with intellectual disabilities as partners in fostering self-determination, social care professionals can encourage social participation and feelings of empowerment. Relationships based on partnership offer people with intellectual disabilities a form of hetero-regulation that can help them overcome challenges to behaving in a fully self-determined way. However, partnership also requires changes in professional practices and attitudes.
\end{abstract}

\section{Introduction}

Current trends in socio-educational research, training and practices all underscore the importance of self-determination among people with intellectual disabilities. Self-determination generally refers to people's ability to make choices that affect their own lives (Wehmeyer, 2005). Such a definition tends to favour a functional model for examining practices intended to support self-

\footnotetext{
* Corresponding author.

E-mail addresses: annick.cudre-mauroux@hefr.ch (A. Cudré-Mauroux), genevieve.pierart@hefr.ch (G. Piérart), carla.vaucher@unil.ch (C. Vaucher).
} 
determination among people with intellectual disabilities (Wehmeyer, 1996); this model has been validated empirically (Shogren et al., 2008). By taking a clinical perspective on support, such a model makes it possible to focus on personal development by proposing ways of learning the skills necessary for self-determination. It highlights various criteria which are generally used to define a self-determined behaviour. To begin with, the behaviour must be accomplished autonomously, that is to say without any undue external influence and in accordance with a person's interests, preferences and aptitudes. It also needs to be self-regulated. This notion refers to people's ability to analyse their behaviour and the range of possible responses before making a decision, as well as their ability to analyse the repercussions of that decision. Furthermore, self-determined behaviour must be the result of psychological empowerment. In other words, people need to develop a sense of control and power over their own lives, allowing them to break free of an "in care" mentality. Finally, self-determined behaviour must reflect a person's self-realization. People need to be able to recognize their strengths and to act accordingly.

The promotion of self-determination among people with intellectual disabilities is significant because these individuals are considered less self-determined than their peers without disabilities (Wehmeyer et al., 2011). Not only are high levels of self-determination positively associated with broader social participation, they also are positively correlated with higher levels of employment (Wehmeyer \& Palmer, 2003), social abilities (Carter, Owens, Trainor, Sun, \& Swedeen, 2009), education (Thoma \& Getzel, 2005), and general quality of life (Lachapelle et al., 2005). Furthermore, higher levels of self-determination facilitate access to education (Palmer, Wehmeyer, Gipson, \& Agran, 2004).

Certain features of intellectual disabilities can hinder self-determination (Shogren, Palmer, Wehmeyer, Williams-Diehm, \& Little, 2012; Wehmeyer et al., 2012; Wehmeyer, Palmer, Shogren, Williams-Diehm, \& Soukup, 2013), including emotional difficulties (Carter, Lane, Pierson, \& Glaeser, 2006), as well as difficulties making choices (Schelly, 2008) and lower levels of cognitive ability (Shogren et al., 2007; Wehmeyer et al., 2012). Intellectual disabilities also affect self-regulation mechanisms (Hickson \& Khemka, 2001), such as self-management, goal-setting, problem-solving, decision-making, and observational skills. Self-regulation therefore encompasses transversal skills used in a variety of settings, skills that are difficult for people with intellectual and cognitive deficits to develop. Examining the social environment of people with intellectual disabilities - family members, acquaintances or social care professionals- is directly relevant to note challenges to self-determination.

The functional model states that self-determination occurs in the context of people's interactions with those around him. Selfdetermination should therefore not be confused with independence. A person may require assistance in order to achieve self-determination (Lachapelle \& Wehmeyer, 2003). The socio-ecological model emphasizes the importance of interactions between people with intellectual disabilities and their environment (Schalock et al., 2010; Shogren, 2013; Walker et al., 2011; Wehmeyer et al., 2011). It highlights the role of contextual influences in the development of self-determination. It seems therefore essential to take both personal characteristics and environmental factors into account when promoting self-determination among people with intellectual disabilities. Indeed, in the context of the relationship between people and their environment, individual characteristics and environmental factors interact in complex ways (Shogren, 2013). The socio-ecological perspective highlights the importance of the reciprocal parts played by people with intellectual disabilities and members of their social environment in fostering their selfdetermined behaviours.

In Switzerland, where we conducted our research, many people with intellectual disabilities still live in residential facilities. Currently, policies of inclusion rely on specialized facilities that offer protected accommodation and employment programs for residents. As a result, the social context of people with intellectual disabilities is largely limited to interactions with professionals from various fields (Marquis \& Jackson, 2000; McVilly, Stancliffe, Parmenter, \& Burton-Smith, 2006). In such a context, however, research underlines the importance of the part played by professionals regarding the social inclusion of residents (McConkey \& Collins, 2010). It is also recognized that the psychological wellbeing of professionals working in residential services, and the influence it may have on their practices, affects the quality of the support they offer to people with intellectual disabilities (Rose, 2011). Our research study therefore recognized relationships with professionals working in these facilities as key environmental factors. Some research has shown the important role of the socio-educational environment in supporting self-determination within an institutional context. In particular, these studies have addressed openness and permissiveness (Walker et al., 2011; Wehmeyer \& Bolding, 2001), attitudes and interventions (Antaki, Finlay, Walton, \& Pate, 2008; Wong \& Wong, 2008), institutional constraints (Stancliffe, Abery, \& Smith, 2000), and professional training (Cooper \& Browder, 2001; Wong \& Wong, 2008).

This paper examines relationships between people with intellectual disabilities and social care professionals in order to better understand the relational dimension of how self-determination develops in everyday practice. We see relationships with social care professionals as a key context for promoting and experiencing self-determination. From a socio-ecological perspective, it would seem important to understand how, in this relational context, the individual characteristics of people who receive support align with the attitudes and behaviours of social care professionals with respect to self-determination. In particular, we emphasize the experiential and phenomenological nature of self-determination in the context of interpersonal relations. In the course of our research project, we observed various ways that people with intellectual disabilities expressed needs regarding self-determination in the context of their relationships with staff, as well as how social care professionals responded to these expressions.

\section{Method}

\subsection{Procedures}

Our exploratory and participatory research study involved participants with intellectual disabilities, raising important ethical issues related to free and informed consent. Indeed, people with intellectual disabilities are especially vulnerable during the 
Table 1

Study participants.

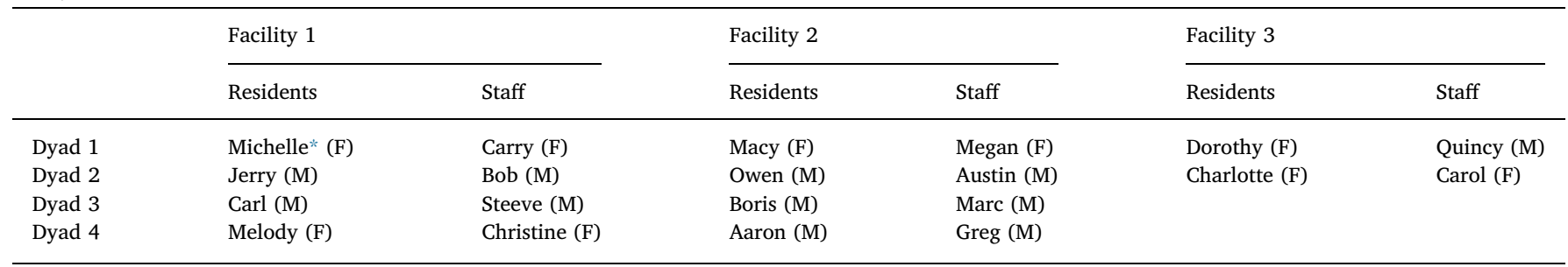

* We have used pseudonyms for all participants.

recruitment process (McDonald \& Kidney, 2012). We therefore ensured that all participants received sufficient information to make an autonomous decision and that they were not subjected to external pressure.

We initially approached several Swiss residential facilities that (a) provided social and practical supports to people with intellectual disabilities and (b) addressed the question of self-determination in their institutional guidelines. We began by sending an introductory document, prepared according to established accessibility guidelines for French-language text (UNAPEI, 2009), to three facilities that expressed an interest in the study. We then gave on-site presentations to interested professionals and residents, using simplified language and visual supports. Residents who chose to participate in the study were asked to complete an adapted consent form. Before data collection began, we held a meeting to address the special needs of participants with intellectual disabilities in terms of scheduling, procedures, and supports.

Each facility was located in a different administrative region of French-speaking Switzerland; one was in a city centre, another was in the suburbs of a different city, and the third was in a village. All three facilities offered accommodation and catering services, and two of them also offered employment services and day programs. The other facility was affiliated with a nearby day program and employment service.

\subsection{Participants}

A total of 20 participants were assigned to 10 dyads at the three different facilities (see Table 1). Each dyad was composed of an adult with mild to moderate intellectual disabilities and a trained social care professional. We chose to group participants this way in order to better observe the relational factors they were likely to experience over the course of the research study. The person with intellectual disabilities had to be capable of participating in a group discussion and received daily practical and social support (housework, food preparation, personal and health care, work activities, recreation, etc.) from the social care professional. The members of each dyad were asked to maintain their relationships for at least one year before the start of the study. Relationships between dyad members were based on daily and ongoing support that sought to help participants with intellectual disabilities develop practical and social skills.

Except for cases where participants spontaneously mentioned upcoming birthdays during focus group discussions, we did not have access to their ages. However, we can assume that a majority of participants—residents and staff members alike-were between the ages of 30 and 50 .

\subsection{Data collection}

We collected data from focus group discussions held at residential facilities. Each focus group included both people with intellectual disabilities and the social care professionals who provided them with support. Indeed, it was important for these two categories of participants to be able to jointly discuss their shared experiences in order to obtain the data necessary for studying their relationships from the perspective of self-determination. Furthermore, the schedule was designed to encourage collaboration between dyad members and to help identify relational and collaborative factors affecting self-determination. When selecting our research setting, we also considered the needs and abilities of people with intellectual disabilities in terms of self-regulation and concentration. None of the participants dropped out of the study before its conclusion.

Our comprehensive, semi-structured approach used open-ended questions to help participants better understand their experiences related to self-determination. Indeed, focus groups have been recognized as an appropriate method for studying the perceptions, attitudes, and experiences of people with intellectual disabilities (Gates \& Waight, 2007; Muir \& Gibbs, 2006). Participants do not need to know how to read or write, and the format is less intimidating than one-on-one interviews. The presence of peers with similar personal characteristics helps encourage active participation, including among those with little perceived social power (Barbour \& Kitzinger, 1999). In the case of our project, both the collective dimension of the focus groups and the social formulation of participants' experiences helped to enrich the discussions. We announced topics in advance, adapting the tempo and atmosphere of the proceedings to the needs of individual participants and the character of the facilities where the different focus groups met. In particular, we considered the needs of people with intellectual disabilities, adapting our language to their level of comprehension and requesting the help of participating social care professionals as facilitators.

Each facility hosted focus group discussions at three-month intervals. The meetings lasted about one hour and included an approximately 20 -minute break following $30 \mathrm{~min}$ of discussion. Over the 10-month period from September 2015 to June 2016 , we 
held four focus group discussions at each facility. However, due to scheduling difficulties, two of the discussions had to be held concurrently, for a total of 13 meetings.

The focus groups discussed four main topics:

- Everyday situations where residents expressed self-determination.

- Ways that people with intellectual disabilities expressed self-determined behaviours in the context of their relationships with social care professionals.

- How staff responded to these expressions of self-determination.

- The relational needs of residents in terms of self-determination.

Between each round of focus group discussions, we asked dyad members to jointly reflect on their experiences through writing, videos, pictures, or any other medium. In particular, we invited them to discuss:

- Situations where the resident expressed self-determined behaviours.

- How each participant perceived and understood self-determination.

- The effectiveness of strategies used in each situation.

These topics were raised during focus group discussions to elicit examples of everyday situations and experiences related to selfdetermination. Indeed, focus group discussions provided our only window on the ideas shared and the material developed by participants at their dyad meetings. We would ask participants to review some of the situations discussed at their dyad meetings, or to share the strategies they used to keep track of these meetings over the course of the research study. However, we did not have direct access to materials and topics discussed at the dyad meetings.

Our interviewing strategies ensured that participants could openly express themselves on issues related to their experiences with self-determination. We reached saturation when the focus groups discussions no longer produced new data related to the discussion topics. The participants have granted us permission to publish the data and we have used pseudonyms is all cases.

All focus groups were held in French. The excerpts presented below were initially translated from French to English by one of the researchers and then the manuscript, including the translated excerpts, was reviewed by a professional translator.

\subsection{Data analysis}

The research team included three researchers -the authors- with varying backgrounds and research interests which confluence may have influenced the way the data was collected, coded and analyzed. Different disciplines and approaches thus converged within this project: the first author joined together an interest in the field of psychology, special education and intellectual disabilies, while the second author had a more anthropological background, with an interest for migration, intercultural perspective, education and intellectual disabilities; the third author, trained in medical anthropology, had experience in the field of health, chronic conditions and communication.

We took an inductive approach to analysing data related to (a) how residents expressed self-determination to social care professionals in everyday situations and (b) how social care professionals responded to these expressions of self-determination. An inductive analysis implies beginning with an area of study and, through a bottom-up approach, lets themes, concepts or models emerge from the data (Strauss \& Corbin, 1998; Thomas, 2006). Transcripts were prepared based on audio recordings of the focus group discussions. Next, we coded the transcripts using two categories of meaning units: expressions of self-determination on the part of residents and staff responses to these expressions of self-determination. Meaning units were further divided into sub-categories, and induced categories related to the broader context of self-determination were added later in the process. Two external raters, both of whom were familiar with the theory of self-determination, conducted a parallel content analysis based on both determined and induced categories. Following discussion, the level of agreement between the analyses increased from $81 \%$ to $91 \%$.

We began data analysis by taking a situational perspective, based on instances described by the dyads where a resident demonstrated self-determination. We gathered data related to these situations, including the responses of social care professionals, to gain an overview of the relational adjustments that occurred within each dyad (Miles \& Hubermann, 2013). Based on the adjustments and readjustments observed within the various dyads, we built a model of different relationship types. Finally, we conducted an additional inductive analysis to identify types of relationship within the context of relational adjustments and readjustments.

\section{Results}

\subsection{Expressions of self-determination by participants with intellectual disabilities in the context of their relationships with social care} professionals

The study allowed us to identify two main ways that residents expressed self-determination in the context of their relationships with staff.

First, participants with intellectual disabilities primarily expressed needs related to self-determination by making specific requests for assistance to social care professionals. These requests seemed to indicate that residents felt they needed support within the context of their relationships with staff before pursuing self-determined behaviours. In these cases, participants with intellectual disabilities 
actively interacted with professionals in order to seek out help achieving a goal related to some aspects of their lives (travel, personal property, moving, entertainment). By taking a collaborative approach, they acknowledged social care professionals as secure partners. For example, after requesting to go on an outing, Melody, a resident, sought help from Christine, a social care professional:

"And what she [Melody] realized was that she would come up with an idea, but that she would need my help with achieving the corresponding goal. So it could be practical details like which train, which bus, at what time, how much it costs-things like that. But she was the one who came up with the ideas." (Christine, professional)

On another occasion, Jerry, a resident, wanted to live in an apartment and asked Bob for his opinion. Their interaction highlights the importance of mutual trust and partnership in a relationship:

"I came up with [the idea]. And then I spoke to Bob to find out what he thought about it ... Our discussions went well when we saw eye to eye. And if not, yes I had my own ideas about the situation. Bob gave me advice on my ideas." (Jerry, resident)

In other situations, participants with intellectual disabilities appeared to adopt a more submissive role by asking professionals for permission to pursue their goals. In this way, they treated social care professionals as authority figures with the power to decide whether they achieved their goals. For instance, Marc, a professional, described how Boris always asked permission before playing a video game:

"But knowing Boris, he always feels the need to... When he sees an educator, he always finds a way of asking, 'Can I play?' Even though he knows that he's free to play whenever he wants." (Marc, professional)

Likewise, Dorothy, a resident, described an implicit rule she followed whenever she invited her boyfriend to visit:

"Yes, before I call to invite him over, I ask if they're [staff] OK with it... We always have to ask because they don't like it when we do things without asking permission." (Dorothy, resident)

Second, in some situations, participants with intellectual disabilities who wanted to pursue a goal choose not to interact with social care professionals or with the broader environment. Residents might simply act according to their own wishes, without regard to the opinion of staff or other environmental parameters. Demonstrating a form of omnipotence, in the sense that they adopted an unlimited and absolute power of decision, they felt empowered to express themselves by achieving their goals. For example, Greg, a professional, explained how Aaron liked to listen to music late at night:

"So we spoke a little about a time when Aaron insisted on listening to his music. He came up with strategies for distracting the educators, and he knew that one of them left at 8:30 p.m. So sometimes he'd turn off his music about 15 min beforehand. 'And when you heard the door close, what happened? You put the music back on, right?' Night after night, we had to tell him to turn off the music... that everyone has to keep quiet after 10 p.m. for those who wanted to sleep. 'But it just wasn't possible, right?'” (Greg, professional)

In these cases, participants with intellectual disabilities were able to make choices and take action independently, in the pursuit of their goals. However, we do not consider these situations to be examples of self-determination. Indeed, they lack the level of selfregulation required by the definition of a self-determined behaviour (Hickson \& Khemka, 2001), insofar as the residents in question failed to analyse the restrictions imposed by their environment and the environmental and social repercussions of their choices.

Other participants with intellectual disabilities demonstrated autonomy by independently pursuing their goals while still taking environmental parameters into account. For example, Macy, a resident, described how she controlled her desire to play music late at night:

“I like to play music at night, because I play djembe. But when it gets too loud, I tell myself, 'No, I need to stop.' So I decide for myself." (Macy, resident)

This type of expression could be considered autonomous insofar as the residents in question were capable of analysing the consequences of their choices and acknowledging the existence of others (Lachapelle \& Wehmeyer, 2003).

\subsection{Responses from social care professionals to expressions of self-determination by participants with intellectual disabilities}

Our analysis of the data revealed a range of responses from social care professionals to expressions of self-determination. We found that staff generally responded positively or/and supportively to requests from residents. And in cases where they could not directly approve such requests, staff members sought to help residents understand the reasons behind this refusal. When people with intellectual disabilities declined to discuss their aims, social care professionals could only respond to the actions residents took in pursuit of their goals.

Participants described several different strategies used by staff when responding to requests related to expressions of self-determination. Interestingly, we found no direct connection between the type of response given by staff and the modes of expression used by residents. In other words, social care professionals did not automatically deny requests made in a submissive manner. This highlights the importance of recognizing the individuality of both parties in the relationship, as reflected in the needs expressed and the strategies used by people with intellectual disabilities, as well as the approaches adopted by staff.

Social care professionals drew on a variety of strategies when accepting requests made by participants with intellectual disabilities. In some cases, they simply offered an opinion, allowing residents to make the final decision on their own. This approach 
showed respect and support for self-determination. For instance, Bob, a professional, emphasized the importance of not trying to influence Jerry when the latter asked to live in an apartment:

"It's not a matter of agreeing or disagreeing. It's a matter of a support. The decisions belong to him [Jerry]. He has to be the one to choose. I do give my opinion, but I'm always careful not to influence him, not to tell him if his idea is good or bad, since that wouldn't be fair." (Bob, professional)

In addition, staff provided support through responses that helped foster reasoning abilities, self-regulation, empowerment, and self-realization.

Social care professionals also responded to the desires of participants with intellectual disabilities based on observations and assumptions. For example, having noticed that Aaron often looked at movie posters, Greg offered to sign him up at the cinema so he could watch movies whenever he wanted:

"I had noticed that he [Aaron] went to look at the movie posters each week. 'I had asked you, Aaron, if you wanted to go to the cinema, since you were always looking at the posters. And then, later, we went to get you a membership card at the cinema." (Greg, professional)

As participants with intellectual disabilities worked to achieve their goals, social care professionals provided motivational support. For example, Jerry was having trouble finding an apartment:

“I also needed a little help. But Bob was like, 'Go for it, go for it, don't lose hope.' ... and then I was starting to get fed up... I said, 'I'm tired, I just want to drop everything and look for an apartment next year instead.' ... Sometimes, Bob told me, 'No Jerry, you'll find one."' (Jerry, resident)

In this case, Bob addressed Jerry's self-regulation difficulties through a logic of hetero-regulation, which helped Jerry achieve higher-level functioning. Hetero-regulation implies to support the person in the context of interactive learning situations (NaderGrosbois, 2007). Staff could then begin offering practical support with scheduling, organization, expenses, or administration.

Furthermore, social care professionals helped participants with intellectual disabilities recognize the practical implications of their requests through self-evaluation. For instance, residents might have to compromise or forego certain options in the course of achieving their goals. As Christine explained regarding Melody:

"We also talked about what arrangements she [Melody] had to make if she wanted to attend [an event] that particular day, like what she had to do, whom she had to contact about this or that... So, for example, I would tell her, 'You want to go to this event, but that will mean that you won't be able to participate in this other activity on the same day.' She therefore had to choose between two things she really enjoys." (Christine, professional)

Sometimes, residents had their choices limited by practical considerations, such as low levels of autonomy, limited financial resources, or institutional constraints. In these cases, staff responses addressed the discrepancy between a goal and the practical likelihood of achieving it.

Often, social care professionals responded to requests from residents by calling for broader collaboration, especially in cases where the request could significantly impact the life of the resident or that of the institution. Staff might choose to consult colleagues, family members of the resident, or professionals from other fields. Such cases highlighted the social care professional's role as a facilitator. However, the involvement of outside actors could also sometimes prevent participants with intellectual disabilities from achieving their goals. For example, Megan explained that staff had to make a rule for Macy's parents. Macy did not want them going in her room when she was not there:

"This year, in consultation with our manager, we developed a strategy for controlling the situation and started saying, 'Stop, this is

Macy's room. It's her own space and you [Macy's parents] can't go in whenever you want.' So we made a rule. If they wanted to enter Macy's room, she had to be there... They couldn't go in her room when she wasn't there." (Megan, professional)

Social care professionals tended to deny requests based on practical considerations. Participants with intellectual disabilities sometimes made requests that prove unrealistic in light of social, material, or temporal constraints-or because of the level of autonomy and abilities required. In these cases, staff responses often aimed to help residents understand why they could not achieve their goals. For instance, Greg underscored the importance of helping Aaron accept not being able to get his way:

"Sometimes there's room for discussion, but other times you need to say no-or you're even required to say no. In those situations, you need to be very careful to support self-determination even if you can't support that particular choice ... Ultimately, the key is to highlight the issues at play so the person can recognize why he or she needs to respect a negative response." (Geg, professional)

Such responses could have emotional consequences for participants with intellectual disabilities, who felt frustrated by rejection. For example, Austin explained how, after rejecting one of Owen's ideas, he waited some time before discussing it:

“Sometimes, with Owen, I've found that his first reaction to a negative response is always, 'Never mind, I'm not going,' or 'I don't want to.' But after a few days, we can discuss the matter again and look for solutions... It's important to give people time. They're disappointed, they're emotional, and emotion always impedes reflection." (Austin, professional)

Social care professionals also sometimes denied requests in cases where participants with intellectual disabilities risked putting themselves in danger. As Steve explained regarding Carl as he wanted to go visit his mother -who lived thirty miles away- by bike: 
"But now, he [Carl] also understands. I firmly said 'no' two or three times because he was putting himself in danger. Now, I think he understands that when I say 'no,' I have a good reason for doing so. Even if he doesn't understand right away, we can always talk later when things calm down." (Steve, professional)

But negative responses can also be experienced positively. As Michelle, a resident, explained:

"Sometimes, they [staff] realize they need to stop us because sometimes we have such crazy ideas. So sometimes we need someone to say, 'Stop, you really need to slow down and take things one step at a time.' Because we don't think and we just keep going... Otherwise, we would be done for, especially me." (Michelle, resident)

Interestingly, in the context of denying requests, social care professionals often pursued intellectual aims, such as fostering the thinking skills of participants with intellectual disabilities or helping them understand a practical reality.

\subsection{Adjustments and relational types}

When analysing how residents expressed self-determination within behaviours and how staff responded, we also undertook an inductive analysis to derive themes related to different relational adjustments, underlying types of relationships, through our interpretations made from the raw data (Thomas, 2006). This analysis was key to achieving a deeper understanding of the complexity that surrounds expressions of self-determination by residents and the responses of staff. Each type of relationship could have specific implications for interventions designed to promote self-determination among people with intellectual disabilities.

\subsubsection{Relational breakdown}

The first relational mode we observed in the situations described by study participants reflects a breakdown in the relationship between the social care professional and the person receiving support. These broken relationships highlight the power that each party can exert over the other, whether consciously or not.

Such breakdowns occurred in situations where people with intellectual disabilities failed to take their environment into account when making choices. More specifically, they neglected to consider the impact of their behaviour on their physical environment, their social environment, or themselves. These residents did not appear to acknowledge their interdependence with their environment. As mentioned above, this type of behaviour cannot be rightly described as self-determined, since self-determination requires recognition of environmental factors through self-regulation. Indeed, self-regulation skills require flexibility and adaptation, as well as an ability to plan ahead and solve problems (Hickson \& Khemka, 2001). Individuals must be conscious of the connections between their behaviour and their environment.

\subsubsection{Partnership}

In relationships based on partnership, social care professionals and participants with intellectual disabilities each made adjustments and readjustments. When their requests were accepted, residents still had to face the difficulties associated with achieving their goals. Likewise, when their requests were denied due to practical constraints, they were expected to actively adapt to those constraints. Indeed, when residents understood why they couldn't pursue their goals, they were better able to accept having their requests denied. As Bob explained:

"We're in a partnership. We take the person's request and consider it in light of the circumstances. It's a real collaboration." (Bob, professional)

Partnership implies a shared will and a mutual ability to maintain a relationship. It requires an effort on the part of both parties. We can therefore define it as a relationship capable of meeting the challenges encountered over time, challenges that are resolved within the relationship itself. Eschewing their implicit position of power, social care professionals must seek to establish a real relationship with the person with intellectual disabilities. Marc told us about this process, while noting that he had not encountered the idea during his training:

"Of course, when you're collaborating, you need to set aside that idea of power because you're sharing power with one, two, or three other people. There's also the idea that, 'I know what's best, I'll make the decision and you'll carry it out.' When you're collaborating, these ideas of power don't matter anymore. But it's not easy. It's true that I wasn't trained to do this sort of thing."

(Marc, professional)

This relational mode can foster self-determination among people with intellectual disabilities, along with help obtained within the environment. Indeed, the evidence suggests that experiencing this type of relationship strongly supports the acquisition of social skills. In turn, these skills gradually allow people receiving support to begin engaging with their broader environment in a selfdetermined manner. These are important factors to consider, given that the literature has called for a better understanding of contextual influences on the development of self-determination, in both research and practice (Shogren, 2013).

\subsubsection{Autonomy}

Our analysis also revealed how participants with intellectual disabilities were capable of displaying autonomy in certain situations. In these cases, the socio-educational relationship was replaced with one defined by a consciousness of the broader environment. We observed this process in situations where residents were capable of making choices on their own while recognizing the limitations 
imposed by the broader environment.

In this context, autonomy in no way implies a breakdown of the relationship with the broader environment. Rather, people with intellectual disabilities display autonomy by finding appropriate moments for removing themselves from the socio-educational relationship and negotiating directly with their environment. Although this autonomy requires a relationship with the broader environment, it can also align with the goals of interventions for supporting self-determination among people with intellectual disabilities (Halpern, Herr, Doren, \& Wolf, 2000; Powers et al., 2001; Wehmeyer, Palmer, Agran, Mithaug, \& Martin, 2000).

\section{Discussion}

Our study's methodology and results highlight the crucial role of relationships with social care professionals in promoting selfdetermination among people with intellectual disabilities. Social context is key to understanding how self-determination develops; it therefore would benefit from being explored from a socio-ecological perspective (Shogren, 2013). Our analysis demonstrates how self-determined behaviour is more likely to be modelled, encouraged and developed within a relationship based on partnership. Such a relationship seems to require continuity and mutual adjustments to ensure that people receiving support are well integrated within their socio-educational environment. It therefore seems to represent an ideal context for helping an individual develop self-determination. Broken relationships, implying a failure to consider one's broader environment, hinder self-determination. People with intellectual disabilities may pursue goals without taking environmental constraints into account, potentially placing themselves or those around them at risk of emotional, social or physical harm. Such a scenario reflects an absence of the adjustment and problemsolving skills apparently required for self-determination (Hickson \& Khemka, 2001). When they did succeed in making decisions autonomously, study participants demonstrated self-regulation skills and an awareness of the broader environment.

Our results suggest that, to be more effective, strategies for promoting self-determination may benefit from focusing on achieving goals within the context of a partnership. In such relationships, social care professionals provide the encouragement, emotional support, and assistance which seems necessary to mediate the broader environment. This helps people with intellectual disabilities recognize the consequences of their choices, take the necessary steps to achieve their goals, and address challenges they encounter while doing so. This kind of hetero-regulated support appears to promote the phenomenological acquisition of self-regulation skills among people with intellectual disabilities. It can also increase their level of empowerment and self-realization, while guiding them toward autonomous action within the broader environment. Furthermore, it highlights the positive influence of the environment on the development of self-determination among people with intellectual disabilities. These various considerations highlight the importance of examining the quality of the bond between people with intellectual disabilities and their socio-educational environment, in the context of the development and expression of self-determination. They also make it possible to discuss the reciprocal roles that define such a relationship from a socio-ecological perspective.

Fostering the partnership seems to require a reorientation of professional attitudes, since partnerships tend to subvert both professional identities and institutional hierarchies. Interventions designed to promote self-determination may therefore benefit from addressing professional attitudes and postures qualitatively, as well as the importance of relationship strategies that support the needs expressed by people with intellectual disabilities (see Cudré-Mauroux, Piérart, \& Vaucher, 2019). Furthermore, the relational dimension of support for self-determination highlights the importance of trying to modify the system in which people with intellectual disabilities live their lives, a concern that aligns with the interactionist approach generally favoured at this time (Fougeyrollas \& Beauregard, 2001). For social care professionals, this would mean being able to recognize expressions of autonomy among people with intellectual disabilities and supporting their efforts in the context of a symmetrical relationship based on partnership. Such a shift calls for a kind of relational adjustment that would ensure support for people with intellectual disabilities in their efforts to achieve self-determination (Tossebro et al., 2012) and, when necessary, in relation to their difficulty in understanding the limits placed on such efforts. Exploring the dynamics between the socio-educational environment and people with intellectual disabilities also highlights the proactive role played by these individuals when they express their needs in terms of self-determination. Indeed, they are required to interact with others, negotiate, and act on their desires within the context of a relationship, and to adjust to the realities they face. In this way, they learn to consciously engage with their environment and to take its characteristics into account when making choices and pursuing goals.

The importance of the reciprocal roles needed for establishing a symmetrical relationship based on partnership underscores the fact that such relationships allow people with intellectual disabilities experience inclusion, participation, and social recognition within a secure space that can gradually expand to encompass a broader context. In terms of support practices, these roles underscore the importance of recognizing the need to feel secure, while also giving people with intellectual disabilities access to a form of emancipatory empowerment. In terms of self-determination, people with intellectual disabilities are best able to achieve emancipation in the context of a relationship where they can count on receiving support whenever they need it.

Our research study was qualitative, inductive and exploratory in nature. It results therefore cannot be generalized. We recognize that our methodology served to encourage participating residents and staff to develop relationships based on partnership. Our results would certainly have been different had we worked with these two groups separately, comparing their viewpoints without first asking them to work together in dyads. On another note, being able to fully identify participants by age could have enriched our analysis by examining how age itself or life experience may influence the type of relationships one is inclined to seek for, favour and maintain. Although they may not have developed spontaneously, the relationships based on partnership observed in the context of our study nevertheless proved to be a driving force for learning among both people with intellectual disabilities and social care professionals. We believe that this type of research study could inspire the implementation of joint training programs. 


\section{Conclusion}

The results of our exploratory research study have various implications for research and theory on self-determination, as well as for the practices and training of professionals who provide support to people with intellectual disabilities. From a socio-ecological perspective, it appears important to pursue a deeper examination of the positive and motivational impact of environmental factors on the expression and development of self-determination. We also believe that the proactive role played by people with intellectual disabilities through their interactions should be better addressed. These considerations could have an important impact on the types of training offered to social care professionals. Indeed, in this context, researchers need to address the question of relationship strategies by exploring how professional attitudes and postures can become more flexible. The spontaneous expressions and needs of people with intellectual disabilities should also be taken into account when making these adjustments, in order to promote inclusion and social participation.

\section{Ethics approval and consent to participate}

All participants consented to participate in the research study through a written agreement and all data was processed in strict confidentiality. An ethics approval request to the Swiss Ethics Committees on research involving humans was not required for this study.

\section{Funding}

This study was financially supported by the Swiss National Science Foundation, the HES-SO University of Applied Sciences and Arts Western Switzerland and the School of Social Work Fribourg.

\section{Contributions}

Study design and conception (Annick Cudré-Mauroux, Geneviève Piérart)

Analysis and interpretation (Annick Cudré-Mauroux, Geneviève Piérart, Carla Vaucher), Drafting the article or revising it critically for important intellectual content (Annick Cudré-Mauroux, Carla Vaucher, Geneviève Piérart)

Final reading and approval of the manuscript and revisions (Annick Cudré-Mauroux, Carla Vaucher, Geneviève Piérart).

\section{Acknowledgements}

This research was supported by the University of Applied Sciences and Arts Western Switzerland. We would like to express our gratitude to all the participants in the study for their time and interest in our research project, and for sharing their opinions with the research team during the course of this research.

\section{References}

Antaki, C., Finlay, W., Walton, C., \& Pate, L. (2008). Offering choices to people with intellectual disabilities: An interactional study. Journal of Intellectual Disability Research, 52(12), 1165-1175.

Barbour, R., \& Kitzinger, J. (1999). Developing focus group research: Politics, theory and practice. London: Sage Publication.

Carter, E. W., Lane, K. L., Pierson, M. R., \& Glaeser, B. (2006). Self-determination skills and opportunities of transition-age youth with emotional disturbance and learning disabilities. Exceptional Children, 72, 333-346.

Carter, E. W., Owens, L., Trainor, A. A., Sun, Y., \& Swedeen, B. (2009). Self-determination skills and opportunities of adolescents with severe intellectual and developmental disabilities. American Journal on Intellectual and Developmental Disabilities, 114(3), 179-192.

Cooper, K. J., \& Browder, D. M. (2001). Preparing staff to enhance active participation of adults with severe disabilities by offering choice and prompting performance during a community purchasing activity. Research in Developmental Disabilities, 22, 1-20.

Cudré-Mauroux, A., Piérart, G., \& Vaucher, C. (2019). The importance of the relational needs of people with learning disabilities in the promotion of self-determination. British Journal of Learning Disabilities. https://doi.org/10.1111/bld.12268 early preview.

Fougeyrollas, P., \& Beauregard, L. (2001). An interactive person-environment social creation. In G. L. Albrecht, K. D. Seelman, \& M. Bury (Eds.). Handbook of disabilities studies (pp. 171-194). Thousands Oaks, CA: Sage Publications.

Gates, B., \& Waight, M. (2007). Reflections on conducting focus groups with people with learning disabilities: Theoretical and practical issues. Journal of Research in Nursing, 12(2), 111-126.

Halpern, A. S., Herr, C. M., Doren, B., \& Wolf, N. K. (2000). NEXT S.T.E.P.: Student transition and educational planning. [Teacher manual, student workbooks, and videotape] (second edition). .

Hickson, L., \& Khemka, I. (2001). The role of motivation in the decision making of people with mental retardation. In H. N. Switzky (Ed.). Personality and motivational differences in persons with mental retardation (pp. 199-255). Mahwah, New Jersey: Lawrence Erlbaum Associates Publishers.

Lachapelle, Y., \& Wehmeyer, M. L. (2003). L’Autodétermination [Selfdetermination]. In M. Tasse, \& D. Morin (Eds.). La déficience intellectuelle [Intellectual deficit] (pp. 203-214). Boucherville, Quebec, Canada: Gaetan Morin.

Lachapelle, Y., Wehmeyer, M. L., Haelewyck, M.-C., Courbois, Y., Keith, K. D., Schalock, R., ... Walsh, P. N. (2005). The relationship between quality of life and selfdetermination: An international study. Journal of Intellectual Disability Research, 49(10), 740-744.

Marquis, R., \& Jackson, R. (2000). Quality of life and quality of service relationships: Experiences of people with disabilities. Disability \& Society, 15, 411-425.

McConkey, R., \& Collins, S. (2010). The role of support staff in promoting the social inclusion of persons with an intellectual disability. Journal of Intellectual Disability Research, 54(8), 691-700.

McDonald, K. E., \& Kidney, C. A. (2012). What is right? Ethics in intellectual disabilities research. Journal of Policy and Practice in Intellectual Disabilities, 9, 27-39.

McVilly, K. R., Stancliffe, R. J., Parmenter, T. R., \& Burton-Smith, R. M. (2006). "I get by with a little help from my friends": Adults with intellectual disabilities discuss loneliness. Journal of Applied Research in Intellectual Disabilities, 19, 191-203. 
Miles, M. B., \& Hubermann, A. M. (2013). Qualitative data analysis. London: Sage Publications.

Muir, W. J., \& Gibbs, S. M. (2006). Research in the psychiatry of learning disability. In C. Freeman, \& P. J. Tyrer (Eds.). Research methods in psychiatry (pp. 252-291). London: Gaskell.

Nader-Grosbois, N. (2007). Vers un modèle intégré de l'autorégulation et de l'hétérorégulation? [Toward an integrative model of self regulation and hetero-regulation?]. In N. Nader-Grosbois (Ed.). Régulation, autorégulation, dysrégulation (pp. 15-30). Wavre: Mardaga.

Palmer, S. B., Wehmeyer, M. L., Gipson, K., \& Agran, M. (2004). Promoting access to the general education curriculum by teaching self-determination skills. Exceptional Children, 70(4), 427-439.

Powers, L. E., Turner, A., Westwood, D., Matuszewski, J., Wilson, R., \& Phillips, A. (2001). Take Charge for the Future: A controlled field-test of a model to promote student involvement in transition planning. Career Development for Exceptional Individuals, 24, 89-104.

Rose, J. (2011). How do staff psychological factors influence outcomes for people with developmental and intellectual disability in residential services? Current Opinion in Psychiatry, 24(5), 403-407.

Schalock, R. L., Borthwick-Duffy, S. A., Bradley, V. J., Buntinx, W. H. E., Coulter, D. L., Craig, E. M., ... Yeager, M. H. (2010). Intellectual disability: Definition, classification, and systems of supports. Washington DC: American Association on Intellectual and Developmental Disabilities.

Schelly, D. (2008). Problems associated with choice and quality of life for an individual with intellectual disability: A personal assistant's reflexive ethnography. Disability \& Society, 23(7), 719-732.

Shogren, K. A. (2013). A social-ecological analysis of the self-determination literature. Intellectual and Developmental Disabilities, 51, $496-511$.

Shogren, K. A., Palmer, S. B., Wehmeyer, M. L., Williams-Diehm, K., \& Little, T. D. (2012). Effect of intervention with the Self-Determined Learning Model of Instruction on access and goal attainment. Remedial and Special Education, 33, 320-330.

Shogren, K. A., Wehmeyer, M. L., Palmer, S. B., Soukup, J. H., Little, T. D., Garner, N., ... Lawrence, M. (2007). Examining individual and ecological predictors of the self-determination of students with disabilities. Exceptional Children, 73, 488-509.

Shogren, K. A., Wehmeyer, M. L., Palmer, S. B., Soukup, J. H., Little, T. D., Garner, N., ... Lawrence, M. (2008). Understanding the construct of self-determination: Examining the relationship between the arc's self determination scale and the american institutes for research self-determination scale. Assessment for Effective Intervention, 33(2), 94-107.

Stancliffe, R. J., Abery, B. H., \& Smith, J. (2000). Personal control and the ecology of community living settings: Beyond living-unit size and type. American Journal on Mental Retardation, 105, 431-454.

Strauss, A., \& Corbin, J. (1998). Basics of qualitative research ( $2^{\text {nd }}$ ed.). Newbury Park, CA: Sage.

Thoma, C. A., \& Getzel, E. E. (2005). "Self-determination is what it's all about": What post-secondary students with disabilities tell us are important considerations for success. Education and Training in Developmental Disabilities, 40(3), 217-233.

Thomas, D. R. (2006). A general inductive approach for analysing qualitative evaluation data. The American Journal of Evaluation, 27(2), 237-246.

Tossebro, J., Bonfils, I. S., Teittinen, A., Tideman, M., Traustadottir, R., \& Vesala, H. T. (2012). Normalization fifty years beyond - Current trend in the Nordic countries. Journal of Policy and Practice in Intellectual Disabilities, 9(2), 134-146.

UNAPEI (2009). L'information pour tous. Règles européennes pour une information facile à lire et à comprendre. [Information for all. European rules for an information easy to read and to understand]. https://www.unapei.org/IMG/pdf/Guide_ReglesFacileAlire.pdf/.

Walker, H. M., Calkins, C., Wehmeyer, M. L., Walker, L., Bacon, A., Palmer, S. B., ... Johnson, D. (2011). A social-ecological approach to promote self-determination. Exceptionality, 19(1), 6-18.

Wehmeyer, M. L. (1996). Self-determination as an educational outcome: Why is it important to children, youth and adults with disabilities? In D. J. Sand, \& M. L. Wehmeyer (Eds.). Self-determination across the life span: Independence and choice for people with disabilities (pp. 15-34). Baltimore: Paul H. Brookes.

Wehmeyer, M. L. (2005). Self-determination and individuals with severe disabilities: Reexamining meanings and misinterpretations. Research and Practice for Persons With Severe Disabilities, 30(113), 120.

Wehmeyer, M. L., \& Bolding, N. (2001). Enhanced self-determination of adults with intellectual disability as an outcome of moving to community-based work or living environments. Journal of Intellectual Disability Research, 45(5), 371-383.

Wehmeyer, M. L., \& Palmer, S. B. (2003). Adult outcomes for students with cognitive disabilities three years after high school: The impact of self-determination. Education and Training in Developmental Disabilities, 38(2), 131-144.

Wehmeyer, M. L., Abery, B. H., Zhang, D., Ward, K., Willis, D., Hossain, W. A., ... Walker, H. M. (2011). Personal self-determination and moderating variables that impact efforts to promote self-determination. Exceptionality, 19, 19-30.

Wehmeyer, M. L., Palmer, S. B., Agran, M., Mithaug, D. E., \& Martin, J. E. (2000). Promoting causal agency: Self-determined learning model of instruction. Exceptional Children, 66, 439-453.

Wehmeyer, M. L., Palmer, S. B., Shogren, K. A., Williams-Diehm, K., \& Soukup, J. (2013). Establishing a causal relationship between interventions to promote selfdetermination and enhanced student self-determination. The Journal of Special Education, 46, 195-210.

Wehmeyer, M. L., Shogren, K. A., Palmer, S. B., Williams-Diehm, K., Little, T. D., \& Boulton, A. (2012). Impact of the Self-Determined Learning Model of Instruction on student self-determination: A randomized-trial placebo control group study. Exceptional Children, 78, $135-153$.

Wong, P. K., \& Wong, D. F. (2008). Enhancing staff attitudes, knowledge and skills in supporting the self-determination of adults with intellectual disability in residential settings in Hong Kong: A pretest-posttest comparison group design. Journal of Intellectual Disability Research, 52(3), 230-243. 